\title{
Pyrimidine-derived Prolinamides as Recoverable Bifunctional Organocatalysts for Enantioselective Inter- and Intramolecular Aldol Reactions under Solvent-free Conditions
}

\author{
Pascuala Vizcaíno-Milla, ${ }^{[\mathrm{a}]}$ José M. Sansano, ${ }^{[\mathrm{a}]}$ Carmen Nájera, ${ }^{\left[{ }^{[a]}\right]}$ Béla Fiser,${ }^{[\mathrm{b}]}$ and Enrique Gómez- \\ Bengoa*[b]
}

Dedicated to Prof. J. Elguero on the ocassion of his 80th birthday

Keywords: Organocatalysis / Aldol reactions / Pyrimidine / Prolinamide / Solvent-free process /

\begin{abstract}
Chiral L-prolinamides 2 containing the $(R, R)$ - and $(S, S)$-trans-cyclohexane-1,2-diamine scaffold and a 2-pyrimidinyl unit are synthesized and used as general organocatalysts for the intermolecular and intramolecular aldol reaction with 1,6-hexanedioic acid as co-catalyst under solvent-free conditions. The intermolecular reaction between ketone-aldehyde and aldehyde-aldehyde must be carried out under wet conditions with catalyst $(S, S)-\mathbf{2 b}$ at $10{ }^{\circ} \mathrm{C}$ affording anti-aldols with high regio-, diastereo- and enantioselectivities. For the Hajos-Parrish-Eder-Sauer-Wiechert (HPESW) reaction both diastereomeric catalysts 2 give similar results at $r$ in the absence of water to give the corresponding Wieland-Miescher ketone and derivatives. Both types of reactions have been scale-up to $1 \mathrm{~g}$ and the organocatalystshave been recovered by extractive work up and reused without appreciable loss of activity. DFT calculations support the stereochemical results for the intermolecular process and the bifunctional role played by the organocatalyst providing a computational comparison of the $\mathrm{H}$-bond networks occurring with catalysts $\mathbf{2 a}$ and $\mathbf{2} \mathbf{b}$.
\end{abstract}

\section{Introduction}

Enamine catalysis constitutes an important branch of asymmetric organocatalysis mainly for aldol, Mannich and Michael reactions and for the $\alpha$-functionalization of carbonyl compounds. ${ }^{[1]}$ A plethora of organocatalysts have been successfully designed for this activation mode being pyrrolidine containing systems such as proline and its derivatives the most efficient ones specially for aldol reactions. ${ }^{[2]}$ Prolinamide derivatives bearing an additional functionality able to form one or two hydrogen bonds provides extra interactions and a more bulky environment. ${ }^{[3]}$ In addition, a higher solubility of prolinamides in organic solvents enhaces the reaction rate and the stereoselectivity. Moreover, they are also suitable for solvent-free aldol processes, which can be performed not only in shorter reaction times but also with only a slight excess of the carbonyl compound acting as nucleophile and lower loading of catalyst. $^{[4]}$ In order to increase the steroselective efficiency of proline-based organocatalysts they have been bonded to a chiral scaffold forming match and mismatch-combinations. $\mathrm{C}_{2-}$ symmetric chiral diamines such as 1,2-diphenylethanediamine, trans-cyclohexane-1,2-diamine and 1,1'-binaphthyl-3,3'-diamine (binam) allow to design organocatalysts bearing two prolinamide units. ${ }^{[2]}$ Another strategy for the preparation of bifunctional organocatalysts is to bond a prolinamide in one of the amino

[a] Departamento de Química Orgánica, Facultad de Ciencias, and Centro de Innovación en Química Avanzada (ORFEO-CINQA), Universidad de Alicante, Apdo. 99, 03080-Alicante, Spain. E-mail: cnajera@ua.es

[b] Departmento de Química Orgánica l, Facultad de Química, Universidad del País Vasco, Apdo. 1072, E-20080 San Sebastián, Spain.

E-mail:enrique.gomez@ehu.es

Supporting information for this article is given via a link at the end of the document.((Please delete this text if not appropriate)) groups and in the other amino group an additional hydrogen bond donating motif. Our group has described that chiral binamderived prolinamides bearing a sulfonamide unit of the type 1a and $\mathbf{1 b}$ can be used as general organocatalysts for inter- and intramolecular aldol reactions under solvent-free conditions under conventional magnetic stirring (Figure 1). ${ }^{[5]}$ However, for the recovery of these types of bifunctional catalysts it was necessary to anchor the sulfonamide unit to a silica gel support by means of gel-sol techniques. ${ }^{[6]}$ We envisaged that transcyclohexane-1,2-diamines, commercially accesible in both enantiomeric forms, can be a more flexible skeleton to anchor the prolinamide that is able to form the enamine intermediates and a 2-aminopyrimidine group to form extra hydrogen bonds with the carbonyl acceptor. We have found that these types of new systems $\mathbf{2} \mathbf{a}$ and $\mathbf{2} \mathbf{b}$, are simple, recoverable and reusable bifunctional organocatalysts for inter- and intramolecular aldol reactions under solvent-free conditions (Figure 1).
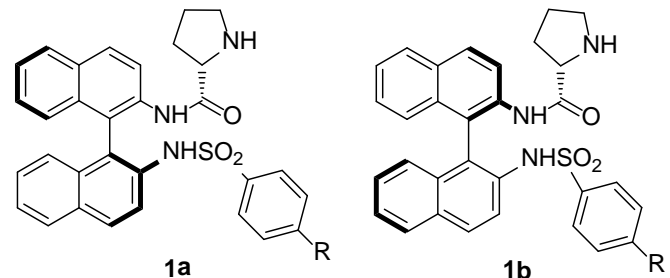

$\mathrm{R}=\mathrm{Me}, \mathrm{CH}_{2} \mathrm{CH}_{2} \mathrm{~S}$-silica gel
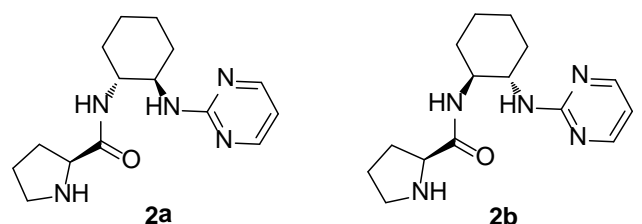

Figure 1. Bifunctional prolinamides derived from binam and trans-1,2cyclohexanediamine. 


\section{Results and Discussion}

Diastereomeric catalyst $\mathbf{2 a}$ was prepared starting from monoBoc-protected $(R, R)$-cyclohexane-1,2-diamine (3) and N-Boc-LPro $(4)^{[7]}$ (Scheme 1$)$. The reaction of compounds $3^{[8]}$ with 2chloropyrimidine under isopropanol reflux in the presence of triethylamine for $36 \mathrm{~h}$, followed by Boc-deprotection with TFA, afforded the 2-aminopyrimidine $(R, R)-5$ in $79 \%$ overall yield. Then, N-Boc-L-Pro (4) was allowed to react with ethyl chloroformate in the presence of triethylamine, followed by in stiu additon of $(R, R)-5$. Finally, TFA-mediated Boc-deprotection allowed the synthesis of $\mathbf{2 a}$ in $54 \%$ overall yield. Similarly, diastereomer $\mathbf{2 b}$ was prepared starting from $(S, S)$-cyclohexane1,2-diamine.

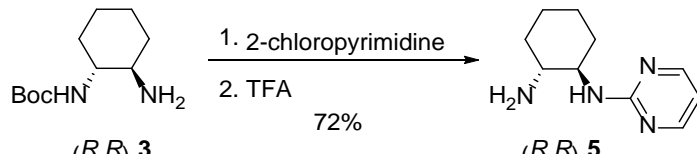

$(R, R)-3$ $(R, R)-5$

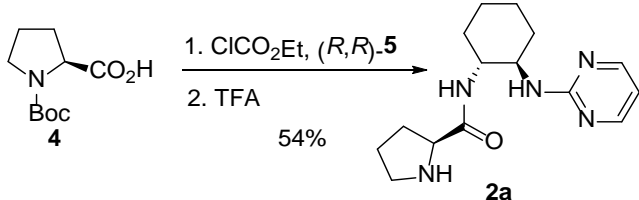

Scheme 1. Synthesis of organocatalyst $\mathbf{2 a}$.
For the optimization reaction studies the aldol reaction between cyclohexanone (6a) and p-nitrobenzaldehyde (7a) was carried out with pyrimidine-prolinamides 2 under solvent-free conditions (Table 1). With $10 \mathrm{~mol}-\%$ of catalysts $\mathbf{2 a}$ or $\mathbf{2} \mathbf{b}$ and in the absence of additives the aldol reaction took place at $\mathrm{rt}$ with full conversion giving product $\mathbf{8 a a}$ in $2: 1$ to $3: 1$ anti:syn diastereomeric ratio and $11 \%$ and $69 \%$ ee, respectively (Table 1 , entries 1 and 2). The addition of $10 \mathrm{~mol}-\%$ of 1,6-hexanedioic acid (HDA) gave similar results, but addition of $1 \mathrm{~mL}$ of water increased notably the ee, and also the diasteroselectivity (Table 1 , entries 3-6). On the other hand, reducing the amount of water to 12 equiv increased mainly the reaction rate (Table 1 , entries 7 and 8). Finally, just lowering the temperature at $10^{\circ} \mathrm{C}$ a notably increment on the anti/syn ratio to $19: 1$ and $24: 1$, respectively, was observed with both catalysts $\mathbf{2} \mathbf{a}$ and $\mathbf{2} \mathbf{b}$ and the ee increased to 90 and $97 \%$, respectively (Table 1, entries 9 and 10). The recovery of catalyst $\mathbf{2} \mathbf{b}$ was carried out performing this model reaction between cyclohexanone (6a) of 4nitrobenzaldehyde (7a) in $1 \mathrm{~g}$ scale. The reaction took place in $36 \mathrm{~h}$ with a higher $51: 1 \mathrm{dr}$, the pure anti-aldol was obtained after recrystallization in $83 \%$ yield and the anti-8aa was obtained in $95 \%$ ee. The catalyst was recovered in $87 \%$ yield after extractive acid-basic work-up (see, SI). After a second run the aldol was obtained in $70 \%$ yield with the same dr and ee and the catalyst recovered in $72 \%$ yield.

Table 1.Optimization of the Intermolecular Aldol Reaction. ${ }^{[a]}$

\begin{tabular}{|c|c|c|c|c|c|c|c|c|}
\hline Entry & 2 & Additive [mol-\%] & $\mathrm{H}_{2} \mathrm{O}$ & $\mathrm{T}\left({ }^{\circ} \mathrm{C}\right)$ & $t(h)$ & Conv. $[\%]^{[\mathrm{b}]}$ & anti/syn $^{[\mathrm{c}]}$ & ee $[\%]^{[\mathrm{d}]}$ \\
\hline 1 & $2 a$ & - & - & 25 & 24 & 100 & $2: 1$ & 11 \\
\hline 2 & $2 b$ & - & - & 25 & 20 & 100 & $3: 1$ & 69 \\
\hline 3 & $2 a$ & $\operatorname{HDA}(10)$ & & 25 & 24 & 100 & $2: 1$ & 20 \\
\hline 4 & $2 b$ & $\mathrm{HDA}(10)$ & - & 25 & 20 & 100 & $2.5: 1$ & 62 \\
\hline 5 & $2 a$ & HDA (10) & $1 \mathrm{~mL}$ & 25 & 24 & 89 & $10: 1$ & 83 \\
\hline 6 & $2 b$ & HDA (10) & $1 \mathrm{~mL}$ & 25 & 24 & 64 & $8: 1$ & 90 \\
\hline 7 & $2 a$ & HDA (10) & $12 \mathrm{eq}$ & 25 & 19 & 100 & $4: 1$ & 85 \\
\hline 8 & $2 b$ & HDA (10) & $12 \mathrm{eq}$ & 25 & 17 & 100 & $7: 1$ & 90 \\
\hline 9 & $2 a$ & HDA (10) & $12 \mathrm{eq}$ & 10 & 24 & 100 & $19: 1$ & 90 \\
\hline 10 & $2 b$ & HDA (10) & $12 \mathrm{eq}$ & 10 & 24 & 100 & $25: 1$ & $97^{[\mathrm{e}\rfloor}$ \\
\hline
\end{tabular}

[a] A mixture of cyclohexanone (1.2 mmol), p-nitrobenzaldehyde $(0.3 \mathrm{mmol}), 2$ (10 mol-\%), additive (see column) and $\mathrm{H}_{2} \mathrm{O}(\mathrm{see}$ column) was magnetically stirred at the temperature and for the time indicated. [b] Conversion based on aldehyde $7 \mathrm{a}\left({ }^{1} \mathrm{H} \mathrm{NMR}, 300 \mathrm{MHz}\right)$. [c] Determined by ${ }^{1} \mathrm{H}$ 
The scope of the intermolecular aldol reaction was studied under the last reaction conditions, catalyst $\mathbf{2 b}(10 \mathrm{~mol}-\%)$, HDA (10 mol-\%), 12 equiv of water at $10^{\circ} \mathrm{C}$ (Table 2). Cyclohexanone (6a) was allowed to react with different aromatic aldehydes 7a-e affording the corresponding anti-aldols 8aa-8ae in good yields (56\%-94\%), diastereo- (90:10 to 96:4) and enantioselectivities ( $8 \%$ to $>99 \%$ ) (Table 2, entries 1-5). Aliphatic aldehydes such as 2,2-dimethoxyacetaldehyde and ethyl glyoxylate were also assayed as acceptors with cyclohexanone. The reaction with an aqueous solution of 2,2-dimethoxyacetaldehyde (60\% wt) was performed without adding water giving aldols $8 \mathbf{a f}^{[8]}$ in $75 \%$ yield as a 6:1 mixture of diastereomers and anti-8af in 97\% ee (Table 2 , entry 6 ). When a $50 \%$ toluene solution of ethyl glyoxylate was used as acceptor, the $\alpha$-hydroxy ester $\mathbf{8 a g}$ was obtained as a $32: 1$ mixture of anti/syn diastereomers in $80 \%$ yield and in $93 \%$ ee for the anti-aldol (Table 2, entry 7 ).
Other cyclohexanone derivatives, such as 4-oxacyclohexanone (6b) gave, by reaction with $p$-nitrobenzaldehyde, the antidiastereomer 8ba in 97:3 dr and in 93\% ee (Table 2, entry 8). The protected 1,3-dihydroxyacetone, 2,2-dimethyl-1,3-dioxan-5one (6c) reacted with 2,2-dimethoxyacetaldehyde (7f) affording 8cf as a 95:5 mixture of anti/syn diastereomers in 68\% yield The protected D-erythro-pentos-4-ulose (8cf) was obtained in $89 \%$ ee (Table 2, entry 9). For comparison L-Pro (30 mol-\%) ${ }^{[9]}$ gave, after $13 \mathrm{~h}$ reaction time, $8 \mathrm{cf}$ in $47 \%$ yield, $90 \%$ de and $83 \%$ ee under the same solvent-free conditions Cyclopentanone $(\mathbf{6 d})$ reacted with $p$-nitrobenzaldehyde $(\mathbf{7 a})$ to give mainly the syn-aldol $\mathbf{8 d a}$ according to the general behavior of cyclopentanone under prolinamide catalysis. Compound 8da was obtained as a 1:3 anti/syn mixture, in 76\% yield in 91\% and $30 \%$ ee, respectively (Table 2 , entry 10 ).

Table 2. Solvent-free Intermolecular Aldol Reaction of Ketones with Aldehydes Organocatalyzed by $\mathbf{2 b}$. $^{\text {[a] }}$

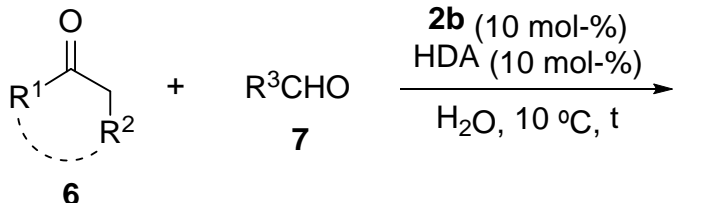

6

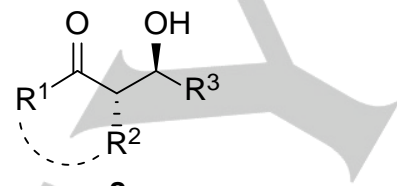

8

\begin{tabular}{|c|c|c|c|c|c|c|c|c|}
\hline Entry & 6 & 7 & $\mathrm{t}[\mathrm{h}]$ & Product & No. & Yield [\%] ${ }^{[b]}$ & anti/syn ${ }^{[\mathrm{c}]}$ & ee $[\%]^{[d]}$ \\
\hline 1 & $6 a$ & $7 a$ & 24 & & $8 a a$ & 89 & $96: 4$ & 97 \\
\hline 2 & $6 a$ & $7 b$ & & & $8 a b$ & 94 & $96: 4$ & $>99$ \\
\hline 3 & $6 a$ & & 48 & & $8 a c$ & $87^{[\mathrm{e}]}$ & $96: 4$ & 93 \\
\hline 4 & $6 a$ & $7 d$ & 24 & & $8 \mathrm{ad}$ & $75^{[\mathrm{e}]}$ & $97: 3$ & 96 \\
\hline 5 & $6 a$ & $7 e$ & 114 & & $8 a e$ & 56 & $90: 10$ & 86 \\
\hline
\end{tabular}


6

$7 f^{[f]}$

48<smiles>COC(O)C(O)C1CCCCC1=O</smiles><smiles>CCOC(=O)C(O)C1CCCCC1=O</smiles><smiles>O=C1CCOCC1C(O)c1ccc([N+](=O)[O-])cc1</smiles><smiles>COC(O)C(O)C1OC(C)(C)OC1=O</smiles>

10

6d

$7 a$

48<smiles>O=C1CCC[C@H]1[C@H](O)c1ccc([N+](=O)[O-])cc1</smiles>

11

$6 e^{[j]}$

$7 a$

48<smiles>CC(=O)C[C@@H](O)c1ccc([N+](=O)[O-])cc1</smiles>

12

$6 f$

$7 a$

60

13

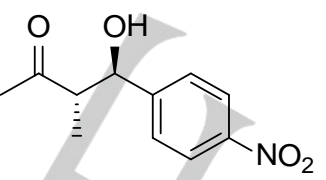

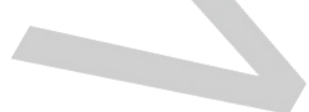<smiles>C=Cc1ccc([N+](=O)[O-])c(O)c1</smiles>

[a] Reaction conditions: catalyst $\mathbf{2 b}(10 \mathrm{~mol}-\%)$, ketone $(1.2 \mathrm{mmol})$, aldehyde $(0.3 \mathrm{mmol})$, water (6 mmol), HDA (10 mol-\%) under magnetic stirring at $10^{\circ} \mathrm{C}$. [b] Isolated yield after column chromatography, based on aldehyde 7. [c] Determined by ${ }^{1} \mathrm{H}$ NMR (300 MHz) for the crude product. [d] Determined by chiral HPLC for the anti-diastereomer. [e] For the anti-isomer. [f]60\% wt aqueous solution. In this case external water was not added. [g] 50\% in toluene. [h] Determined from its benzoate by chiral HPLC. [i] $91 \%$ ee forthe anti-diastereomer. [j] 20 equiv of acetone were used. [k] A 2:1 mixture of regioisomers $\mathbf{8 f a}$ and the iso-8fa' were obtained. [l]A 83:17 mixture of regioisomers $\mathbf{8 g a}$ and the iso-8ga' were obtained.

On the other hand, when acyclic ketones such as acetone, butanone and methoxyacetone were submitted to the aldol reaction with $p$-nitrobenzaldehyde products 8ea-8ga were obtained. In the case of acetone a large excess of 20 equiv must be used in order to achieve good conversions and high 99\% ee (Table 2, entry 11). In the case of butanone a 2:1 regioisomeric mixture of anti/syn-8fa and iso-8fa' aldols was obtained in $81 \%$ yield (Table 2, entry 12). The anti/syn aldols 8 fa were isolated as a 91:9 diastereomeric mixture and the major diastereomer in $86 \%$ ee. Similarly, methoxyacetone gave a 83:17 mixture of regioisomers 8ga and iso-8ga' (Table 2, entry 13). Aldols 8ga were isolated as a 82:18 mixture of anti/syn diastereomers and the anti-aldol in $84 \%$ ee.

Catalyst $\mathbf{2 b}$ (30 mol-\%), in the presence of of 1,6-hexanedioic acid (30 mol-\%) and water (12 equiv), promoted the cross-aldol reaction between propanal $(7 \mathrm{~h}, 5$ equiv) and $p$ nitrobenzaldehyde (7a) at $0{ }^{\circ} \mathrm{C}$ under solvent-free conditions for 3 d. After subsequent reduction with $\mathrm{NaBH}_{4}$ in $\mathrm{MeOH}$, the corresponding diol 9ha was isolated in $52 \%$ overall yield as $3: 1$ 
mixture of anti/syn diastereomers and the anti-diol being obtained in $90 \%$ ee (Scheme 2 ).
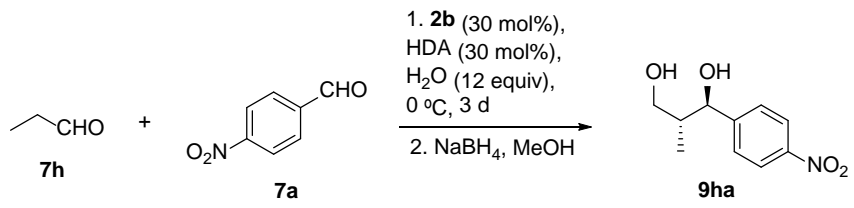

Scheme 2.Solvent-free aldehyde-aldehyde cross-aldol reaction.

Next, the intramolecular Hajos-Parrish-Eder-Sauer-Wiechert $(\mathrm{HPESW})^{10}$ aldol reaction was assayed with triketone $10 \mathrm{a}$ using both catalysts $\mathbf{2} \mathbf{a}$ and $\mathbf{2 b}$ under solvent-free conditions (Table 3 ). In this case, the use of wet conditions at rt with prolinamide $\mathbf{2 a}$ produced the Mischler-Wieland ketone 11a in a lower ee and longer reaction time (Table 3, compare entries 1 and 2). When using $\mathbf{2} \mathbf{b}$ as organocatalyst the reaction needed $20 \mathrm{~h}$ instead of $10 \mathrm{~h}$ and 11a was obtained in slightly lower $86 \%$ ee instead of
$89 \%$ ee (Table 3, compare entries 2 and 3 ). When the reaction temperature was lowered to $10^{\circ} \mathrm{C}, 11 \mathrm{a}$ was obtained in 87 and $88 \%$ ee, respectively (Table 3 , entries 4 and 5). Therefore, it was preferable to carry out the reaction at rt independently of the organocatalyst (Table 2, entries 2 and 3 ). For the allyl substituted triketone $\mathbf{1 0 b}$ andusing catalyst $\mathbf{2 a}$, the bicyclic alkenone $\mathbf{1 1} \mathbf{b}$, a precursor of (-)-anominine ${ }^{[11]}$ was obtained in $77 \%$ yield and $84 \%$ ee (Table 3 , entry 6 ). In the case of triketone 10c, the corresponding alkenone 11c was obtained in $53 \%$ yield and moderate $77 \%$ ee (Table 3 , entry 7). Cyclopentanedione derivative $10 \mathrm{~d}$ gave the aldol condensation product $11 \mathrm{~d}$ in better ee when using prolinamide $\mathbf{2} \mathbf{a}$ than $\mathbf{2} \mathbf{b}$ as organocatalysts(Table 3 , compare entries 8 and 9). The recovery of catalyst $\mathbf{2 a}$ was carried out performing the synthesis of the Wieland-Miescher ketone (11a) in $1 \mathrm{~g}$ scale. The reaction took place in $4 \mathrm{~h}$ in $81 \%$ yield and in $89 \%$ ee. The catalyst was recovered in $79 \%$ yield after extractive acid-basic work-up (see, $\mathrm{SI}$ ). After a second run 11a was obtained with the same ee in $79 \%$ yield and the catalyst was recovered in $74 \%$ yield.

Table 3.Solvent-free Intramolecular Aldol HPESW Reaction of Triketones Organocatalyzed by $\mathbf{2 a}$ and $\mathbf{2} \mathbf{b}{ }^{[a]}$

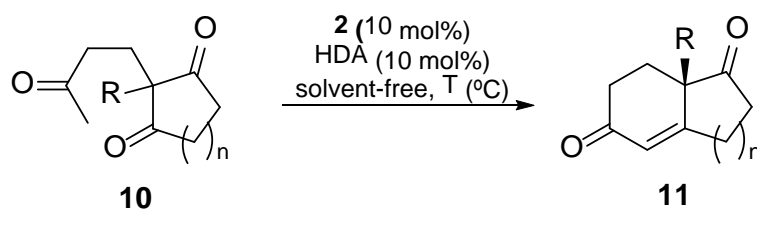

\begin{tabular}{|c|c|c|c|c|c|c|c|c|c|c|}
\hline Entry & $\mathrm{R}$ & $n$ & 10 & 2 & $\mathrm{H}_{2} \mathrm{O}$ & $\mathrm{T}\left[{ }^{\circ} \mathrm{C}\right]$ & $\mathrm{t}[\mathrm{h}]$ & Product & Yield [\%] $]^{[b]}$ & ee $[\%]^{[c]}$ \\
\hline 1 & $\mathrm{Me}$ & 2 & $10 a$ & $2 a$ & $12 \mathrm{eq}$ & 25 & 20 & $11 a$ & (99) & 75 \\
\hline 2 & $\mathrm{Me}$ & 2 & $10 a$ & $2 a$ & - & 25 & 10 & $11 a$ & 92 & 89 \\
\hline 3 & $\mathrm{Me}$ & 2 & $10 a$ & $2 b$ & - & 25 & 20 & $11 a$ & (99) & 86 \\
\hline 4 & $\mathrm{Me}$ & 2 & $10 a$ & $2 a$ & - & 10 & 17 & $11 a$ & (99) & 87 \\
\hline 5 & $\mathrm{Me}$ & 2 & $10 a$ & $2 b$ & - & 10 & 17 & $11 a$ & (99) & 88 \\
\hline 6 & allyl & 2 & $10 \mathrm{~b}$ & $2 a$ & & 25 & 16 & $11 b$ & 77 & 84 \\
\hline 7 & benzyl & 2 & $10 \mathrm{c}$ & $2 a$ & - & 25 & 16 & $11 c$ & 53 & 77 \\
\hline 8 & $\mathrm{Me}$ & 1 & $10 d$ & $2 a$ & - & 25 & 16 & 11d & 80 & 79 \\
\hline 9 & $\mathrm{Me}$ & 1 & $10 d$ & $2 b$ & - & 25 & 16 & 11d & (99) & 68 \\
\hline
\end{tabular}

[a] Reaction conditions: catalyst 2 (10 mol-\%), ketone $(0.3 \mathrm{mmol}), \mathrm{HDA}(10 \mathrm{~mol}-\%)$ under magnetic stirring. [b] Isolated yield after column chromatography, in parenthesis conversions determined by ${ }^{1} \mathrm{H}$ NMR. [c] Determined by chiral HPLC.

In order to get further insight into the mechanism of the catalyst activity and the origin of the enantioselectivity for the intermolecular aldol reaction, Density Functional Theory (DFT) calculations $^{[12]}$ were carried out. We were specially interested in analyzing the $\mathrm{H}$-bond network responsible for the efficiency of the catalyst. The geometry optimizations were done at the B3LYP/6-31+G** level ${ }^{[13]}$ of theory in a solvent model system (CPCM, water as solvent). ${ }^{[14]}$ Single point energies were obtained for the optimized structures at the M06-2X/6-311+G** 
(CPCM, water) level, ${ }^{[15]}$ to better account for the polarization of the $\mathrm{H}$-bonds, the developing charges and the dispersion effects of such large molecules. Although at a high computational cost, we decided to compute the exact structures used in the experimental studies (enamines $\mathbf{A}$ and $\mathbf{B}$,Figure 2). These enamines are formed in the reaction between $p$ nitrobenzaldehyde and catalysts $\mathbf{2 a}$ and $\mathbf{2 b}$, respectively, and due to the presence of an acidic cocatalyst, they are assummed to be protonated to a great extent in the experimental conditions. Furthermore, the protonated species are predicted to be much more active, forming stronger $\mathrm{H}$-bonds than the neutral ones. The most intriguing data to be explained is the similar enantioselectivity achieved with the diastereomeric catalysts $\mathbf{2 a} / \mathbf{2} \mathbf{b}$, meaning that the stereogenic center of the pyrrolidine ring is dictating the selectivity of the reaction.

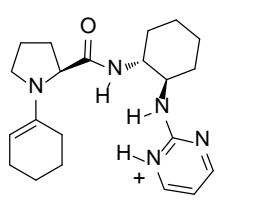

enamine $\mathbf{A}$ cycloxenanone $+2 a$ or

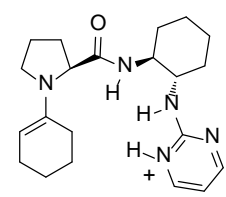

enamine $\mathbf{B}$

cyclohexanone $+\mathbf{2 b}$<smiles>O=Cc1ccc([N+](=O)[O-])cc1</smiles>

\section{Enamines Aand $\mathbf{B}$ and $p$-nitrobenzaldehyde}

Figure 2. Species computed in this study. consistently activated by $\mathrm{H}$-bonding with two of the three available $\mathrm{NH}$ moieties present in enamines $\mathbf{A}$ and $\mathbf{B}$, meaning that manifold combinations exist depending on which $\mathrm{NH}$ groups are involved in the activation. After an extensive conformational search, the most feasible structures for each diastereomer are TSA-anti and TSA-syn (Figure 3), which interestingly, contain a similar $\mathrm{H}$-bond activation pattern. In both cases, the amidic $\mathrm{(Ha}$ and the pyrimidinium $(H c) \mathrm{NH}$ groups are correctly positioned to activate the carbonylic oxygen, whereas the participation of $\mathrm{Hb}$ is severely hindered by geometrical restrictions. Indeed, $\mathrm{Hb}$ points are away from the reaction center in the most stable conformations. The energy difference between TSA-anti and TSA-syn is 0.7 or $2.7 \mathrm{kcal} / \mathrm{mol}$, depending on the computational model used, and is enough to explain the anti-selectivity provided by $\mathbf{2} \mathbf{a}$ in the experimental conditions.
In all the located transition structures, the $p$-nitrobenzaldehyde is
TSA-anti

$\mathrm{G}=0$
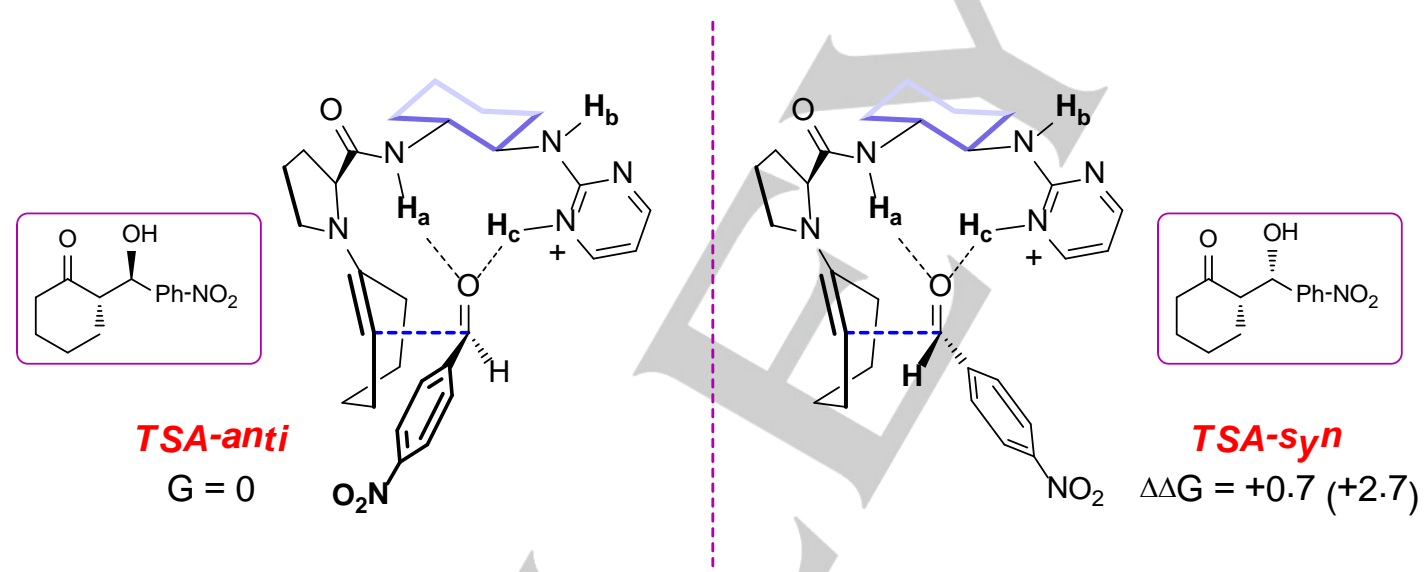<smiles>[I-]</smiles>

Figure 3. Transition states for the reaction between enamine $A$ and $p$-nitrobenzaldehyde. Gibbs Free Energies computed at $M 06-2 X / 6-311+G * \star$ level. Value in parenthesis corresponds to B3LYP energy.

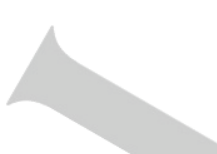

The computed Ha-O and Hc-O bond distances (ca. $1.8 \AA$ and $1.6 \AA$, respectively) are very similar in both structures and do not determine the preference for the formation of the anti-transition state, which instead is related to the available space to locate the phenyl ring of the $p$-nitrobenzaldehyde around the forming $\mathrm{C}-\mathrm{C}$ bond. This effect is common to other related prolinamide systems. Thus, the approaching $p$-nitrobenzaldehyde prefers to accommodate its aromatic ring on the outer most position (to the left of our view in Figure 4), avoiding the steric interactions with the cyclohexane and cyclohexanone rings. However, as suggested by the qualitative analysis of the 3-D structure (Figure
4), there is still enough space available in the innner area to accommodate the aryl ring, in line with the low-medium energy difference (1-3 kcal/mol) between anti and syn diastereoisomers with this catalyst. 


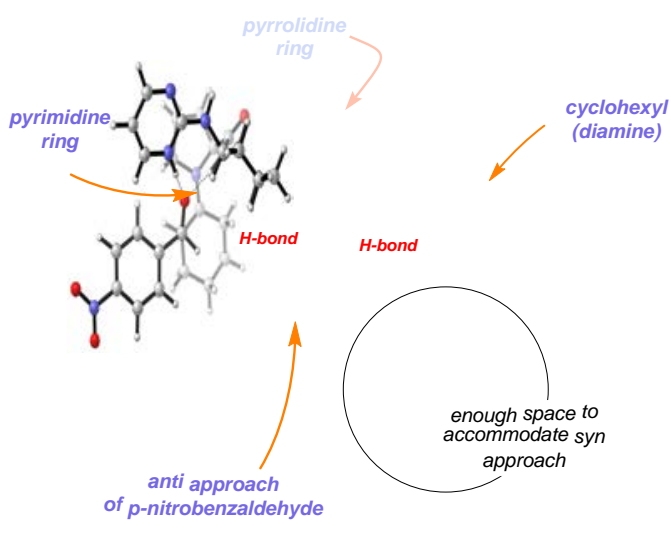

Enamine B ( $p$-nitrobenzaldehyde $+2 \mathbf{2 b})$
On the other hand, the different configuration in enamine $\mathbf{B}$ induces a profound change in the orientation of the $\mathrm{NH}$ groups, especially $H b$ and $H c$, which point to opposite directions with respect to enamine A. As a result, $H b$ is better suited for carbonyl activation (Figure 5), whilst $\mathrm{Hc}$ points away from the reaction center. As before, the computed $\mathrm{Ha}-\mathrm{O}$ and $\mathrm{Hb}-\mathrm{O}$ bond distances (ca. $1.8 \AA$ and $1.6 \AA$, respectively) are very similar in both structures. Interestingly, the energy difference is significantly increased in this case to $4.4 \mathrm{kcal} / \mathrm{mol}(7.7 \mathrm{kcal} / \mathrm{mol}$ at B3LYP level), justifying the good selectivity obtained with catalyst $\mathbf{2 b}$.

Figure 4. Front view of the TSA_anti transition structure. The forming C-C bond appears eclipsed in the center of the figure, in a Newman projection.
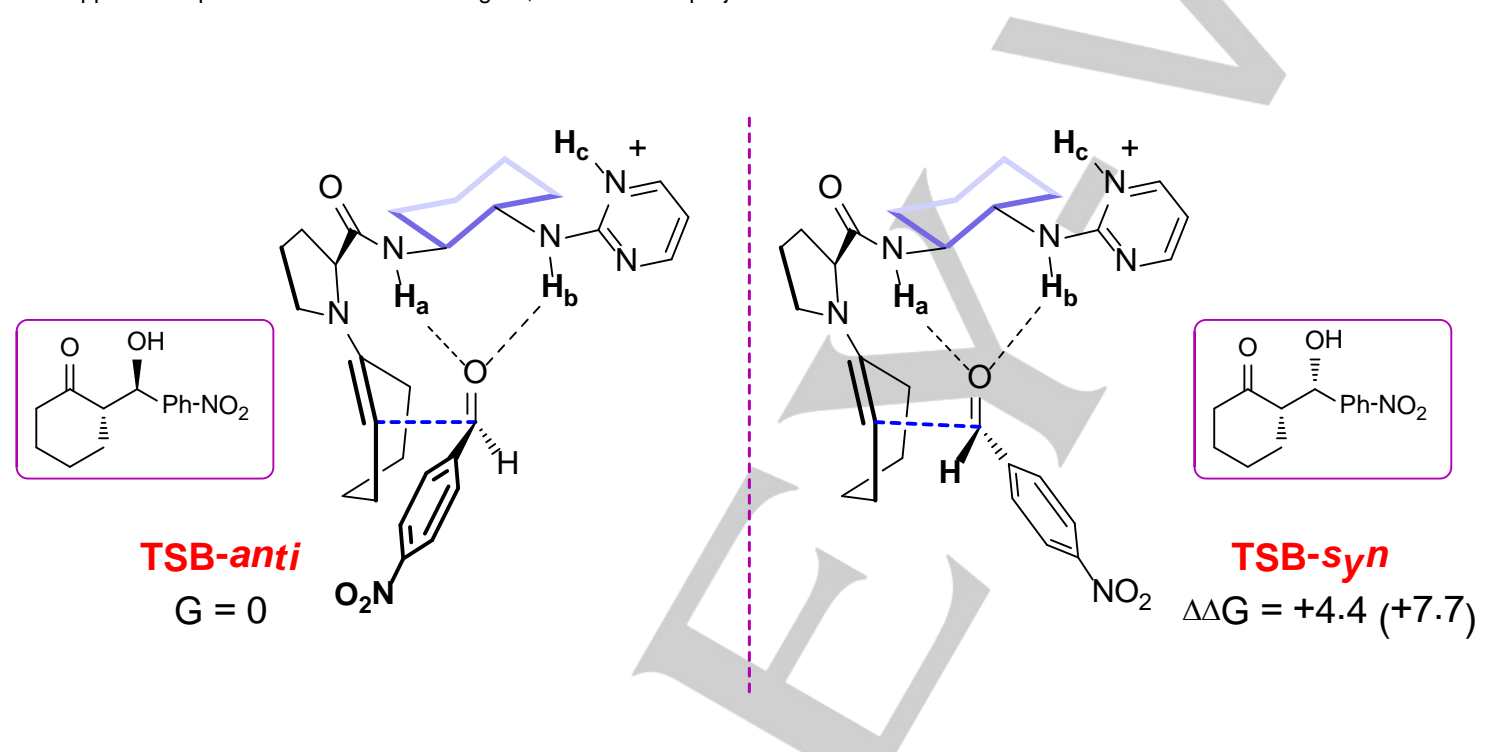

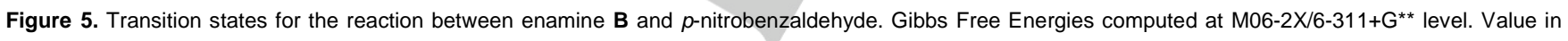
parenthesis corresponds to B3LYP energy.

The main reason for the higher computed selectivity can be observed in the 3D-representation of TSB-anti (Figure 6). The involvement of $H b$, in the catalyst approach of the pyrimidinyl ring to the reaction center, blocking the space available to accommodate the phenyl ring in the syn approach, appears in the comparison between Figures 4 and 6 . Thus, the computational results show a better performance for $\mathbf{2 b}$ than for $\mathbf{2 a}$, in agreement with the experimental data. However, the experimental difference between both catalysts and the diastereoselectivity, in general, is lower than the one predicted by the computational results. In this regard, water is present in a large amount in the reaction media, and it is well known that water molecules are able to weaken the intramolecular $\mathrm{H}$-bonds, making the transition states less rigid, loosening the internal restrictions and lowering the final diastereoselectivities. We believe that even the use of a solvent model system in this type of calculations is not able to reliably mimic the effect of the bulk water in terms of absolute energy values. Nevertheless, the computational results are in good agreement with the experimental data and show the right reactivity/selectivity trend. The computed transition structures are also informative about the $\mathrm{H}$-bond pattern responsible for the reactivity, which can help to the development of new improved catalysts. 


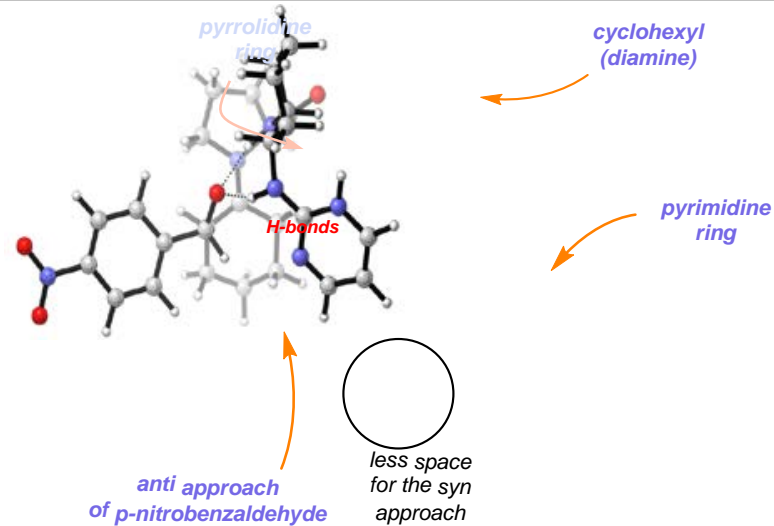

Figure 6. Front view of the TSB_anti transition structure. The forming C-C bond appears eclipsed in the center of the figure, in a Newman projection.

\section{Conclusion}

We have shown that pyrimidine-derived prolinamides are useful recoverable catalysts for inter- and intramolecular aldol reactions under solvent-free conditions in the presence of 1,6-hexanedioic acid as cocatalysts. The use of water (12 equiv) has a notable influence in the diastero- and enantioselectivity only in the intermolecular processes for ketone-aldehyde and aldehydealdehyde aldol reactions. DFT calculations show that the activation of the aldehyde is attained by a double $\mathrm{H}$-bond with the $\mathbf{N H}$ groups of the catalysts $\mathbf{2 a}$ and $\mathbf{2} \mathbf{b}$, explaining the preferential formation of the anti-diastereoisomer in both cases.

\section{Experimental Section}

Synthesis of catalysts 2 . A mixture of $3^{[7]}(3.27 \mathrm{~g}, 15.25 \mathrm{mmol})$, triethylamine $(2.53 \mathrm{~mL}, 18.31 \mathrm{mmol})$ and 2-chloropyrimidine $(2.09 \mathrm{~g}, 18.31 \mathrm{mmol})$ in 2-propanol was stirred for $36 \mathrm{~h}$ at $80^{\circ} \mathrm{C}$ under argon atmosphere. The mixture was concentrated in vacuo and the residue was dissolved in $\mathrm{CH}_{2} \mathrm{Cl}_{2}(10 \mathrm{~mL})$ and washed with $\mathrm{H}_{2} \mathrm{O}(3 \times 20 \mathrm{~mL})$. After removal of the solvent under reduced pressure the resulting residue was purified by flash chromatography (hexane/ ethyl acetate) to give $3.52 \mathrm{~g}$ of Boc-protected 5 (72\%). The resulting solid residue was dissolved in dichloromethane $(110 \mathrm{~mL})$ and trifluoroacetic acid $(9.08 \mathrm{~mL}, 120 \mathrm{mmol})$ was added at $0^{\circ} \mathrm{C}$. The resulting mixture was stirred for $4 \mathrm{~h}$ atrt. Then, the solvents were removed under reduced pressure and the residue was dissolved in $\mathrm{CH}_{2} \mathrm{Cl}_{2}$ (30 $\mathrm{mL})$ and extracted with $\mathrm{H}_{2} \mathrm{O}(3 \times 30 \mathrm{~mL})$. The aqueous layer was treated with $2 \mathrm{~N} \mathrm{NaOH}$ solution until basic $\mathrm{pH}$ and extracted with $\mathrm{CH}_{2} \mathrm{Cl}_{2}(3 \times 60 \mathrm{~mL})$. The organic layer was dried over $\mathrm{MgSO}_{4}$, filtered and the solvents were removed under reduced pressure to yield $2.64 \mathrm{~g}$ of $\mathbf{5}$ ( $90 \%$ yield).

To a solution of Boc-L-proline $4(3.24 \mathrm{~g}, 13.74 \mathrm{mmol})$ and triethylamine $(2.1 \mathrm{~mL}, 15.11 \mathrm{mmol})$ in dry $\mathrm{CH}_{2} \mathrm{Cl}_{2}(30 \mathrm{~mL})$ at 0 ${ }^{\circ} \mathrm{C}$ was added dropwise ethyl chloroformate $(1.72 \mathrm{~mL}, 18.13$ $\mathrm{mmol})$. After stirring the resulting solution for $30 \mathrm{~min}$ at $0{ }^{\circ} \mathrm{C}$, a solution of 5 (2.64 g, $13.74 \mathrm{mmol})$ dissolved in dry $\mathrm{CH}_{2} \mathrm{Cl}_{2}$ (15 $\mathrm{mL}$ ) was added over $15 \mathrm{~min}$ and was stirred overnight at rt under argon atmosphere. The mixture was washed with saturated aqueous solutions of $\mathrm{KHSO}_{4}(2 \times 30 \mathrm{~mL})$ and $\mathrm{NaHCO}_{3}(2 \times 30$ $\mathrm{mL})$ and finally with brine $(2 \times 30 \mathrm{~mL})$. The organic layer was dried over $\mathrm{MgSO}_{4}$, filtered and the solvents were removed under reduced pressure. The resulting residue was purified by flash chromatography (hexane/ethyl acetate) to afford $3.42 \mathrm{~g}$ of Bocprotected 2 (64\%). The resulting solid was dissolved in $\mathrm{CH}_{2} \mathrm{Cl}_{2}$ $(82 \mathrm{~mL})$ and trifluoroacetic acid $(6.85 \mathrm{~mL}, 89.1 \mathrm{mmol})$ was added. The mixture was stirred for $4 \mathrm{~h}$ and the solvents were removed under reduced pressure. The residue was dissolved in $\mathrm{CH}_{2} \mathrm{Cl}_{2}$ $(20 \mathrm{~mL})$ and extracted with $\mathrm{H}_{2} \mathrm{O}(3 \times 20 \mathrm{~mL})$. The aqueous layer was treated with $2 \mathrm{~N} \mathrm{NaOH}$ solution until basic $\mathrm{pH}$ and extracted with $\mathrm{CH}_{2} \mathrm{Cl}_{2}(3 \times 60 \mathrm{~mL})$. The organic layer was dried over $\mathrm{MgSO}_{4}$, filtered and the solvents were removed under reduced pressure to give $2(84 \%)$.

(R)-N-[(1R,2R)-2-(Pyrimidin-2-ylamino)cyclohexyl]pyrrolidine-2carboxamide (2a): Yield $54 \%$; $[\alpha] D^{26}=+34.90$ (c 1, $\mathrm{CHCl}_{3}$ ). White solid, mp $141{ }^{\circ} \mathrm{C} .{ }^{1} \mathrm{H}$ NMR $\delta: ~ 8.23(\mathrm{~d}, \mathrm{~J}=4.7 \mathrm{~Hz}, 2 \mathrm{H}), 7.85$ $(\mathrm{d}, \mathrm{J}=8.1 \mathrm{~Hz}, 1 \mathrm{H}), 6.47(\mathrm{t}, \mathrm{J}=4.8 \mathrm{~Hz}, 1 \mathrm{H}), 5.39(\mathrm{~d}, \mathrm{~J}=8.0 \mathrm{~Hz}$, $1 \mathrm{H}), 3.92-3.81(\mathrm{~m}, 1 \mathrm{H}), 3.72$ (ddd, $J=19.7,10.9,3.9 \mathrm{~Hz}, 1 \mathrm{H})$, $3.63(\mathrm{dd}, \mathrm{J}=9.2,5.1 \mathrm{~Hz}, 1 \mathrm{H}), 2.79(\mathrm{dt}, \mathrm{J}=10.0,6.9 \mathrm{~Hz}, 1 \mathrm{H})$, $2.45(\mathrm{dt}, \mathrm{J}=10.1,6.3 \mathrm{~Hz}, 1 \mathrm{H}), 2.19-2.01(\mathrm{~m}, 3 \mathrm{H}), 2.01-1.91$ (m, 1H), $1.85-1.71(\mathrm{~m}, 2 \mathrm{H}), 1.61(\mathrm{td}, \mathrm{J}=12.9,5.6 \mathrm{~Hz}, 1 \mathrm{H})$, $1.50-1.26(\mathrm{~m}, 5 \mathrm{H}), 1.24-1.14(\mathrm{~m}, 1 \mathrm{H}) .{ }^{13} \mathrm{C}$ NMR $\delta: 175.72$ $(\mathrm{C}=\mathrm{O}), 162.49$ ( $\mathrm{ArC}), 158.05(\mathrm{ArCH}), 110.31(\mathrm{ArCH}), 60.48$ $(\mathrm{CH}), 54.64(\mathrm{CH}), 53.63(\mathrm{CH}), 47.09\left(\mathrm{CH}_{2}\right), 33.09\left(\mathrm{CH}_{2}\right), 32.70$ $\left(\mathrm{CH}_{2}\right), 30.83\left(\mathrm{CH}_{2}\right), 25.77\left(\mathrm{CH}_{2}\right), 25.15\left(\mathrm{CH}_{2}\right), 24.95\left(\mathrm{CH}_{2}\right) . \mathrm{IR}$ (v): 3311, 1644, 1582, 1561, 1511, 1450, $1413 \mathrm{~cm}^{-1}$. HRMS (ES) calcd.for ${ }_{15} \mathrm{H}_{24} \mathrm{~N}_{5} \mathrm{O}\left(\mathrm{MH}^{+}\right)$290.1981, found 290.1967.

(R)- $N$-[(1S,2S)-2-(pyrimidin-2-ylamino)cyclohexyl]pyrrolidine-2carboxamide (2b): Yield $54 \%$. $[\alpha]_{D}^{26}=+52.70$ (c 1.1, $\mathrm{CHCl}_{3}$ ). Yellow oil. $\mathrm{R}_{f}=0.75(9: 1, \mathrm{EtOAc} / \mathrm{MeOH}) .{ }^{1} \mathrm{H}$ NMR $\delta: 8.24(\mathrm{~d}, \mathrm{~J}=$ $4.8 \mathrm{~Hz}, 2 \mathrm{H}), 7.76(\mathrm{~d}, \mathrm{~J}=7.3 \mathrm{~Hz}, 1 \mathrm{H}), 6.48(\mathrm{t}, \mathrm{J}=4.8 \mathrm{~Hz}, 1 \mathrm{H})$, $5.51(\mathrm{~d}, \mathrm{~J}=7.6 \mathrm{~Hz}, 1 \mathrm{H}), 3.88-3.65(\mathrm{~m}, 2 \mathrm{H}), 3.51(\mathrm{dd}, \mathrm{J}=9.1$, $5.4 \mathrm{~Hz}, 1 \mathrm{H}$ ), 2.88 (qt, $J=10.1,6.5 \mathrm{~Hz}, 2 \mathrm{H}), 2.27-2.11(\mathrm{~m}, 1 \mathrm{H})$, $2.07-1.97(\mathrm{~m}, 2 \mathrm{H}), 1.93(\mathrm{br}, 2 \mathrm{H}), 1.85-1.70(\mathrm{~m}, 3 \mathrm{H}), 1.70-$ $1.58(\mathrm{~m}, 2 \mathrm{H}), 1.45-1.22(\mathrm{~m}, 4 \mathrm{H}) .{ }^{13} \mathrm{C}$ NMR $\delta: 175.46(\mathrm{C}=\mathrm{O})$, $162.55(\mathrm{ArC}), 158.01(\mathrm{ArCH}), 110.34(\mathrm{ArCH}), 60.52(\mathrm{CH}), 54.91$ $(\mathrm{CH}), 53.79(\mathrm{CH}), 47.20\left(\mathrm{CH}_{2}\right), 32.75\left(\mathrm{CH}_{2}\right), 32.72\left(\mathrm{CH}_{2}\right), 30.74$ $\left(\mathrm{CH}_{2}\right), 26.07\left(\mathrm{CH}_{2}\right), 24.98\left(\mathrm{CH}_{2}\right), 24.90\left(\mathrm{CH}_{2}\right)$. IR $(v)$ : 3271, 1648, 1585, 1564, 1516, 1449, $1416 \mathrm{~cm}^{-1}$. HRMS (El+) calcd.for $\mathrm{C}_{15} \mathrm{H}_{23} \mathrm{~N}_{5} \mathrm{O}\left(\mathrm{M}^{+}\right)$289.1903, found 289.1908.

General Procedure for Intermolecular Aldol Reactions. To a mixture of the corresponding aromatic aldehyde $(0.3 \mathrm{mmol})$, catalyst $2 \mathrm{~b}(8.6 \mathrm{mg}, 0.03 \mathrm{mmol})$, hexanedioic acid $(4.38 \mathrm{mg}$, $0.03 \mathrm{mmol})$ and water $(64.8 \mu \mathrm{L}, 3.6 \mathrm{mmol})$ at $10^{\circ} \mathrm{C}$ was added the corresponding ketone $(1.2 \mathrm{mmol})$. The reaction was stirred until the aldehyde was consumed (monitored by TLC). Then, the crude product was diluted in EtOAc and washed with $\mathrm{NH}_{4} \mathrm{Cl}$ saturated solution, dried over anhydrous $\mathrm{MgSO}_{4}$ and concentrated in vacuo. The residue was purified by flash chromatography (hexane/ethyl acetate) to yield the pure aldol product. In the case of the reaction between propanal and $p$ nitrobenzaldehyde an excess of 5 equiv of propanal were used. After the same work-up the residue was dissolved in $\mathrm{MeOH}(1$ $\mathrm{mL})$ and the $\mathrm{NaBH}_{4}(12 \mathrm{mg}, 0.3 \mathrm{mmol})$ were added at $0^{\circ} \mathrm{C}$. The mixture was stirred for $1 \mathrm{~h}$ and then the solvent was evaporated. The resulting residue was purified by flash chromatography (hexane/ EtOAc: $4 / 1$ ) to give pure diol 9 ha in $52 \%$ overall yield. 
General Procedure for Intramolecular Aldol Reactions. To the catalyst $\mathbf{2 b}(8.6 \mathrm{mg}, 0.03 \mathrm{mmol})$ and hexanodioic acid $(4.38$ $\mathrm{mg}, 0.03 \mathrm{mmol})$ the triketone $10(0.3 \mathrm{mmol})$ was added at $25^{\circ} \mathrm{C}$. The reaction was stirred during the time required (monitored by TLC, see Table 3). The residue was purified by flash chromatography (hexane/ethyl acetate) to yield the pure aldol product 11.

\section{Acknowledgements}

The Spanish Ministerio de Ciencia e Innovación (MICINN) (projects CTQ2010-20387, and Consolider Ingenio 2010, CSD2007-00006), the Spanish Ministerio de Economia y Competitividad (MINECO) (projects CTQ2013-43446-P and CTQ2014-51912-REDC), FEDER, the GeneralitatValenciana (PROMETEO 2009/039 and PROMETEOII/2014/017), the Basque Government (GV Grant IT-291-07), the FP7 Marie Curie Actions of the European Commission via the ITN ECHONET network (MCITN-2012-316379) and the Universities of Alicante and Basque Country are gratefully acknowledged for financial support. We also thank SGlker (UPV-EHU) for allocation of computational resources.

\section{Supporting Information}

General methods, ${ }^{1} \mathrm{H}$ and ${ }^{13} \mathrm{C}$ NMR spectra copies and HPLC chromatograms of all compounds and DFT calculation results are provided in the supporting information. This material is available free of charge.

\section{References and Footnotes}

[1] Science of Synthesis, Asymmetric Organocatalysis 1, Lewis Base and Acid Catalysts, B. List, Ed.; Thieme: Stuttgart, 2012.

[2] For the first proline catalyzed intermolecular aldol reaction, see: a) X. H. Liu, L. L. Lin, X.-M. Feng, Chem. Commun. 2009, 48, 6145-6158; b) B. List, R. A. Lerner, C. F. Barbas III, J. Am. Chem. Soc. 2000, 122, 2395-2396.

[3] For recent reviews, see: a) B. M. Trost, C. S. Brindle, Chem. Soc. Rev. 2010, 39, 1600 E1632; b) P. M. Pihko, I. E. Majander, A. Erkkilä,Top. Curr. Chem. 2010, 291, 29-75; c) X. H. Chen, J. Yu, L.-Z. Gong, Chem. Commun. 2010, 46, $6437-$ 6448; d) S. K. Panday, Tetrahedron: Asymmetry 2011, 22, 1817-1847; e) G. Guillena, C. Nájera, D. J. Ramón, In Enantioselective Organocatalyzed Reactions; Mahrwald, R., Ed.; Springer: Heidelberg, 2011; Vol. II, P. 245-342; f) M. M. Heravi, S. Asadi, Tetrahedron: Asymmetry 2012, 23, 14311465; g) V. Bisai, A. Bisai, V. K. Vinod, Tetrahedron 2012, 68, 4541-4580; h) J. Mlynarski, S. Bas, Chem. Soc. Rev. 2014, 43, 577-587; i) L. Albrecht, H. Jiang, K. A. Jørgensen, Chem. Eur. J. 2014, 20, 358-368.

[4] For recent reviews on the use of solvent-free conditions for enantioselective aldol reactions, see: a) J. G. Hernández, E. Juaristi, Chem. Commun. 2012, 48, 5396-5409; b) A. BañónCaballero, G. Guillena, C. Nájera, Mini Rev. Org. Chem. 2014, 11, 118-128.

Eur. J. Org. Chem.
[5] a) G. Guillena, C. Nájera, S. F. Viózquez, Synlett 2008, 3031-3035; b) B. Bradshaw, G. Etxebarria-Jardí, J. Bonjoch, S. F. Viózquez, G. Guillena, C. Nájera, Adv. Synth. Catal. 2009, 351, 2482-2490; c) S. F. Viózquez, G. Guillena, C. Nájera, B. Bradshaw, G. Etxebarria-Jardí, J. Bonjoch, Org. Synth. 2011, 88, 317-329; d) B. Bradshaw, G. Etxebarria-Jardí, J. Bonjoch, S. F. Viózquez, G. Guillena, C. Nájera, Org. Synth. 2011, 88, 330-341; e) A. Bañón-Caballero, G. Guillena, C. Nájera, Green Chem. 2010, 12, 1599-1606; f) A. Bañón-Caballero, G. Guillena, C. Nájera, Helv. Chim. Acta. 2012, 95, 1831-1841; g) F. J. N. Moles, G. Guillena, C. Nájera, RSC Adv. 2014, 4, 99639966.

For seminal aldol reactions promoted by L-prolinamides, see: a) Z. Tang, F. Jiang, L.-T. Yu, X. Cui, L.-Z. Gong, A.Q. Mi, Y.-Z. Jiang, Y.-D. Wu J. Am. Chem. Soc. 2003, 125, 5262-5263; b) Z. Tang, F. Jiang, X. Cui, L.-Z. Gong, A.-Q. Mi, Y.-Z. Jiang, Wu, Y.-D. Proc. Natl. Acad. Sci. U.S.A. 2004, 101, 5755-5760; c) Z. Tang, Z.-H. Yang, X.-H. Chen L.-F. Cun, A.-Q. Mi, Y.-Z. Jiang, L.-Z. Gong, J. Am. Chem. Soc. 2005, 127, 9285-9289; d) X.-H. Cheng, J. Sun, C. Wang, Y. Zhang, S. Wei, F. Jiang, Y. Wu, Chem. Commun. 2006, 215-217; e) J.-R. Chen, X.-Y. Li, X.-N. Xing, W.-J. Xiao, J. Org. Chem. 2006, 71, 81988202.

[6] A. Bañón-Caballero, G. Guillena, C. Nájera, E. Faggi, R. M. Sebastián, A. Vallribera, Tetrahedron2013, 69, 1307-1315.

[7] For the same process using binam-prolinamides as organocatalysts, see: F. J. N. Moles, A. Bañón-Caballero, G. Guillena, C. Nájera, Tetrahedron: Asymmetry 2014, 25, 1323-1330.

[8] D. W. Lee, H.-J. Ha, W. K. Lee, Synth. Commun.2007, 37, 737-765.

[9] Y. Hayashi, S. Aratake, T. Itoh, T. Okano, T. Sumiya, M. Shoji, Chem. Commun. 2007, 957-959.

[10] For a review about the Wieland-Miescher ketone and analogues, see: B. Bradshaw, J. Bonjoch, Synlett 2012 337-356.

[11] B. Bradshaw, G. Etxebarria-Jardí, J. Bonjoch, J. Am Chem. Soc. 2010, 132, 5966-5967.

[12] Calculations were performed with the Gaussian 09 suite of programmes; M. J. Frisch, G. W. Trucks, H. B. Schlegel, G. E. Scuseria, M. A. Robb, J. R. Cheeseman, G. Scalmani, V. Barone, B. Menucci, G. A. Petersson, H. Nakatsuji, M. Caricato, X. Li, H. P.Hratchian, A. F. Izmaylov, J. Bloino, G. Zheng, J. L. Sonnenberg, M. Hada, M. Ehara, K. Toyota, R. Fukuda, J. Hasegawa, M. Ishida, T. Nakajima, Y. Honda, O. Kitao, H. Nakai, T. Vreven, J. A., Jr. Montgomery, J. E. Peralta, F. Ogliaro, M. Bearpark, J. J. Heyd, E. Brothers, K. N. Kudin, V. N. Staroverov, R. Kobayashi, J. Normand, K Raghavachari, A. Rendell, J. C. Burant, S. S. Lyengar, J. 
Tomasi, M. Cossi, N. Rega, J. M. Millam, M. Klene, J. E. Knox J. B. Cross, V. Bakken, C. Adamo, J. Jaramillo, R. Gomperts, R. E. Stratmann, O. Yazyev, A. J. Austin, R. Cammi, C. Pomelli, J. W. Ochterski, R. L. Martin, K. Morokuma, V. G. Zakrewski, G. A.Voth, P.Salvador, J. J. Dannenberg, S. Dapprich, A. D. Daniels, O. Farkas, J. B. Foresman, J. V. Ortiz, J. Cioslowski, D. J. Fox, Gaussian 09, Revision D.01, Gaussian, Inc., Wallingford CT, 2009.

[13] a) C. Lee, W. Yang, R. G. Parr, Phys. Rev. B 1988, 37, 785789; b) A. D. Becke, J. Chem. Phys. 1993, 98, 5648-5652; c) W. Kohn, A. D. Becke, R. G. Parr, J. Phys. Chem. 1996, 100 12974-12980.

[14] a) E. Cancès, B. Mennucci, J. Tomasi, J. Chem. Phys. 1997, 107, 3032-3047; b) J. Tomasi, B. Mennucci, E. Cancès, J. Mol. Struct. (Theochem) 1999, 464, 211-226.

[15] Y. Zhao, D. G.Truhlar, Theor. Chem. Acc.2008, 120, 215-241. 
Entry for the Table of Contents (Please choose one layout)

Layout 1:

\section{FULL PAPER}

Pyrimidine-derived Prolinamides as Recoverable Bifunctional

Organocatalysts for Enantioselective Inter- and Intramolecular Aldol

Reactions under Solvent-free

Conditions

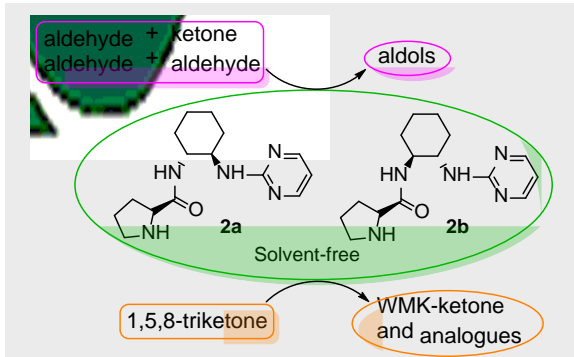

Pascuala Vizcaíno-Milla, José M.

Sansano, Carmen Nájera, * Béla Fiser, and Enrique Gómez-Bengoa*

Page No. - Page No.

Title 